\title{
The spatial and temporal patterns of falciparum and vivax malaria in Perú: 1994-2006
}

\author{
Gerardo Chowell*1,2, Cesar V Munayco ${ }^{3}$, Ananias A Escalante ${ }^{4}$ and F \\ Ellis McKenzie ${ }^{2}$
}

\begin{abstract}
Address: ${ }^{1}$ Mathematical, Computational \& Modeling Sciences Center, School of Human Evolution and Social Change, Arizona State University, Tempe, Arizona, USA, ${ }^{2}$ Division of Epidemiology and Population Studies, Fogarty International Center, National Institutes of Health, Bethesda, Maryland, USA, ${ }^{3}$ Ministry of Health, Perú Jr Camilo Carrillo 402, Jesús María-Lima 11, Perú and ${ }^{4}$ School of Life Sciences, Arizona State University, Tempe, Arizona, USA

Email: Gerardo Chowell* - gchowell@asu.edu; Cesar V Munayco - cmunayco@dge.gob.pe; Ananias A Escalante - Ananias.Escalante@asu.edu; F Ellis McKenzie - mckenzel@mail.nih.gov

* Corresponding author
\end{abstract}

Published: 27 June 2009

Malaria Journal 2009, 8:142 doi:10.1186/1475-2875-8-142
Received: 27 February 2009

Accepted: 27 June 2009

This article is available from: http://www.malariajournal.com/content/8/I//42

(c) 2009 Chowell et al; licensee BioMed Central Ltd.

This is an Open Access article distributed under the terms of the Creative Commons Attribution License (http://creativecommons.org/licenses/by/2.0), which permits unrestricted use, distribution, and reproduction in any medium, provided the original work is properly cited.

\begin{abstract}
Background: Malaria is the direct cause of approximately one million deaths worldwide each year, though it is both preventable and curable. Increasing the understanding of the transmission dynamics of falciparum and vivax malaria and their relationship could suggest improvements for malaria control efforts. Here the weekly number of malaria cases due to Plasmodium falciparum (1994-2006) and Plasmodium vivax (1999-2006) in Perú at different spatial scales in conjunction with associated demographic, geographic and climatological data are analysed.
\end{abstract}

Methods: Malaria periodicity patterns were analysed through wavelet spectral analysis, studied patterns of persistence as a function of community size and assessed spatial heterogeneity via the Lorenz curve and the summary Gini index.

Results: Wavelet time series analyses identified annual cycles in the incidence of both malaria species as the dominant pattern. However, significant spatial heterogeneity was observed across jungle, mountain and coastal regions with slightly higher levels of spatial heterogeneity for $P$. vivax than $P$. falciparum. While the incidence of $P$. falciparum has been declining in recent years across geographic regions, $P$. vivax incidence has remained relatively steady in jungle and mountain regions with a slight decline in coastal regions. Factors that may be contributing to this decline are discussed. The time series of both malaria species were significantly synchronized in coastal $(\rho=$ $0.9, P<0.000 \mathrm{I})$ and jungle regions $(\rho=0.76, \mathrm{P}<0.000 \mathrm{I})$ but not in mountain regions. Community size was significantly associated with malaria persistence due to both species in jungle regions, but not in coastal and mountain regions.

Conclusion: Overall, findings highlight the importance of highly refined spatial and temporal data on malaria incidence together with demographic and geographic information in improving the understanding of malaria persistence patterns associated with multiple malaria species in human populations, impact of interventions, detection of heterogeneity and generation of hypotheses. 


\section{Background}

Malaria is the most significant vector borne disease of humans; it is the direct cause of approximately one million deaths each year, though it is both preventable and curable. Most malaria in humans is due to Plasmodium falciparum and Plasmodium vivax [1], which are generally transmitted by the same species of Anopheles outside Africa.

Nowadays, developing strategies for malaria elimination is considered a global health priority [2]. Although reaching such ambitious goal may not be possible, the available tools will allow reducing the global burden of malaria if they are properly deployed. Thus, a key element for malaria elimination programmes is a good understanding of the malaria transmission dynamics in time and space. This is especially important in areas with low and intermediate seasonal transmission, such as those found in South America. There, previous elimination efforts, with the use of chloroquine and DDT, succeeded in vast areas during the 1970's. While most of the attention has been devoted to $P$. falciparum in Africa, an important element in malaria elimination programs outside Africa is $P$. vivax, a major challenge given that it requires an extended treatment in order to eradicate hypnozoites. Unfortunately, there are still a limited number of studies considering the joint dynamic of these two parasites, $P$. falciparum and $P$. vivax, in time and space. In this investigation, the temporal and spatial trends of these parasites in Perú are explored as an example of the complex dynamic of these parasites in areas with seasonal malaria outside Africa. In South America, severe malaria caused by $P$. falciparum formerly occurred only at Ecuadorian, Colombian, and Brazilian borders while P. vivax was the most important malaria parasite in the region in terms of its morbidity [3]. However, the incidence of falciparum malaria increased dramatically in Perú in the early 1990s, with a seven-fold increase of malaria incidence between 1990 and 1996 [4]. Nowadays, Perú is ranked second after Brazil in terms of the number of malaria cases in South America. Specifically, the Northern Peruvian Amazon (Loreto department comprising about one fourth of the total surface area of Perú), with a population clustered in town and villages throughout the Amazon tributary system, has been the epicenter of the malaria epidemic since the early 1990 s [3]. While cases of falciparum malaria occur mostly in the jungle areas of Perú, $P$. vivax malaria is endemic in the coastal and mountain as well as jungle areas [5]. Moreover, $P$. vivax has replaced $P$. falciparum as the dominant species since 2000 [3].

In this paper, the weekly time series of malaria notifications from the Ministry of Health of Perú are used to analyse the spatial and temporal trends of $P$. falciparum (1994-2006) and P. vivax (1999-2006) malaria across jungle, mountain and coastal areas. The goal here is to increase the understanding on periodicity patterns, persistence and spatial heterogeneity associated with $P$. falciparum and $P$. vivax malaria at different spatial scales including national, geographic and province levels. Findings could shed light to public health authorities on how to effectively distribute resources for malaria control programmes at the national level.

\section{Methods}

Perú is located on the Pacific coast of South America between the latitudes: -3 degrees $S$ to -18 degrees $S$. It shares borders with Bolivia, Brazil, Chile, Colombia, and Ecuador (Figure 1). Perú total population is about 29 million, heterogeneously distributed over a surface area of $1,285,220 \mathrm{~km}^{2}$ with distinctive landscapes including a western coastal plain, the eastern jungle of the Amazon and the Andes Mountains separating coastal and jungle areas (Figure 1). The country is divided into 25 administrative regions composed of 195 provinces [6].

Perú's weather varies from tropical by the Amazon to temperate and glacial in the Andes mountain range, while it is dry by its coast. Specifically, the jungle (rainforest) has two main seasons namely a May-October dry season, with high temperatures and warm nights (with the exception of June, when temperatures can drop significantly at night) and a November-April rainy season, with temperatures reaching $36^{\circ} \mathrm{C}$ and heavy rainfall that causes rivers to rise considerably leading to flooding on the smaller tributaries [3]. The mountain range region also has a May-October dry season, but characterized by clear, sunny days and cold nights, and a November-April rainy season, with heaviest rainfall during the months of January and February and mild daytime temperature that drops at night. The coastal region has an April-November winter season, with cloudy and cool days, and a hot and dry summer December-March, except for the northern coast with higher temperatures and rainfall in the summer.

\section{Data sources}

The Directorate General of Epidemiology of Perú's Health Ministry is in charge of epidemiological surveillance, which is carried out from a network of over 6,000 geographically distributed notifying units. Perú's epidemiological passive surveillance system includes $95 \%$ of the health centers, and has collected weekly malaria data since 1994. All symptomatic individuals presenting fever, chills, headache and general malaise that had been in a malaria endemic area are routinely tested for the malaria parasites by microscopy on site or at the closest accredited laboratory. Notification of malaria cases is mandatory and is carried out weekly. Malaria patients receive free treatment in accordance with national guidelines. Plasmodium falciparum symptomatic cases have been reported since 1994 while mandatory notification of $P$. vivax did not start until 1999. For each of the provinces the weekly 


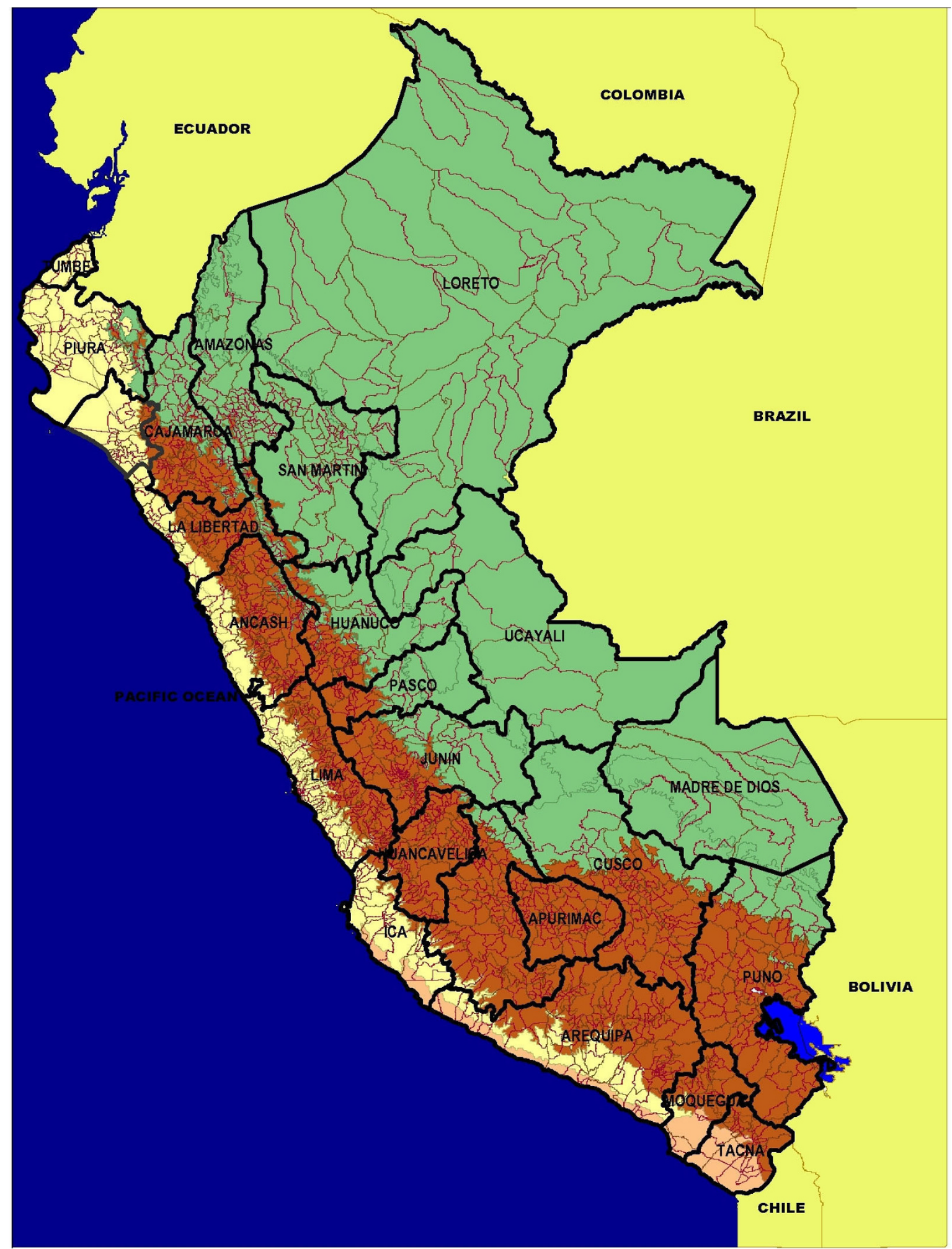

Figure I

Map of Perú with political boundaries of 195 provinces and 25 regions. The geography of Perú covers a range of features, from a western coastal plain (yellow), the Andes Mountains in the center (brown), and the eastern jungle of the Amazon (green). The total population of Perú is about 29 million heterogeneously distributed in an area of I,285,220 km². 
number of cases at reported symptom onset of $P$. falciparum during the period 1994-2006 and $P$. vivax cases during the period 1999-2006 were obtained from the Health Ministry's Directorate General of Epidemiology. A total of 163 provinces reported malaria cases sometime during the period of interest (1994-2006), of which only 78 reported $P$. falciparum cases. Reports of mixed infections were rare.

\section{Population, geographic, and climate data}

The population size of the Peruvian provinces during the years 1994-2006 was obtained from the National Institute of Statistics and Informatics of Perú [7]. The population density of each province (people $/ \mathrm{km}^{2}$ ) is estimated by dividing the province population size by the surface area $\left(\mathrm{km}^{2}\right)$ [8]. These averages ranged from a mean of 22.3 people $/ \mathrm{km}^{2}$ in the mountain range, to 12.38 in the jungle areas, and 172 in the coastal areas (Additional file 1). Each province is classified according to its geographic location as coastal $(n=77)$, mountain $(n=89)$, or jungle area $(n=29$, see Figure 1$)$.

Weekly climate time series were obtained from meteorological stations located in 28 provinces distributed across Perú during the period 1994-2006. Out of the 28 meteorological stations, 13 were located in coastal areas, eight in mountain areas, and seven in jungle areas. Climate data included mean, minimum, and maximum temperature (Fahrenheit) and precipitation (inches) [9].

\section{Time series analysis of $P$. falciparum and $P$. vivax malaria across geographic regions}

Periodic patterns were analysed through wavelet spectral analysis [10-12], disease persistence and critical community size [13-16], and spatial heterogeneity by applying two methods derived from econometrics and previously applied in infectious disease epidemiology, the Lorenz curve and the summary Gini index [see [17-20]].

\section{Wavelet spectral analysis}

Wavelet time series analysis [10-12] has received increasing attention in the last few years as a means of disentangling the non-stationary spatial and temporal dynamics of infectious disease and ecological systems [21-24]. In the temporal evolution of the number of disease cases, the presence of an annual cycle would indicate a single epidemic period per year in the time series while, for example, a biennial pattern characterizes an epidemic period every two years. Wavelet time series analyses are primarily powerful in detecting changes in epidemic periodicity (e.g., switch from biennial to annual cycles). Here the wavelet power spectrum (using the Morlet wavelet as in previous studies [21-24]) was used to investigate variations in the dominant periodic cycles across the time series using freely available software [25]. The weekly time series were log transformed to manage the variability in the amplitude of the time series.

\section{Critical community size}

Several studies have addressed the problem of disease persistence as a function of community size in island and non-island populations (e.g. [13-16,26]). It is therefore of interest to identify a "critical" community size, across geographic regions, above which malaria typically persists. Determining the effective or critical community size for a particular "invasion" is a complex matter because of variations in herd immunity, immigration rates, the possibility of disease reintroductions in the population, and the nature of human interactions. The persistence of malaria was assessed from the proportion of weeks with no malaria reports for each of the provinces in the weekly time series as has been used in previous studies [26].

The possibility of a critical population density (people per $\mathrm{km}^{2}$ ) was also evaluated, but no-significant association was found between population density and the proportion of weeks with no malaria reports ( $P$. falciparum or $P$. vivax).

\section{Spatial heterogeneity}

Spatial variations in attack rates have not been extensively studied. Here, the Lorenz curve and associated summary Gini index at the province level, an approach derived from econometrics, are used to quantify spatial heterogeneity of malaria [17-20]. The Lorenz curve is a graphical representation of the cumulative distribution function of a probability distribution; in this case it represents the proportion of malaria cases associated with the bottom $\gamma \%$ of the population comprised by the provinces previously ranked by case incidence rates. Equal attack rates (no heterogeneity) result in a first diagonal Lorenz curve. On the other hand, perfectly unbalanced distributions give rise to a vertical Lorenz line (maximum heterogeneity). Most empirical attack rate distributions lie somewhere inbetween.

The Gini index summarizes the statistics of the Lorenz curve (ranging between 0 and 1). It is calculated as the area between the Lorenz curve and the diagonal representing no heterogeneity. A large Gini index indicates high heterogeneous attack rates, that is, a situation where the highest attack rates are concentrated in a small proportion of the population. A Gini index of zero indicates that attack rates are directly proportional to population size (no heterogeneity).

\section{Results \\ Temporal patterns of P. falciparum and P. vivax at the national level}

Overall the mean annual incidence rates of $P$. falciparum in Perú during 1994-2006 ranged from 57.3 cases per 
100,000 individuals in 2006 to 686 cases per 100,000 individuals in 1998 while the mean annual incidence of $P$. vivax during 1999-2006 ranged from 201 cases per 100,000 in 2000 to 461 cases per 100,000 in 1999. Figure 2 shows the overall temporal trend of the malaria burden due to P. falciparum (1994-2006) and P. vivax (19992006). For both species, wavelet time series analysis indicated that annual cycles have the highest power. Results also suggest a triennial pattern for the $P$. falciparum series during 1998-2003 and a strong biennial cycle for P. vivax during 2002-2004 (Figure 2). Inspection of the aggregated data at the national level (1999-2006) indicates that both malaria species follow a significantly synchronized dynamical process. In fact, the weekly counts aggregated at the national level of $P$. vivax and $P$. falciparum are significantly correlated (Spearman $\rho=0.62, \mathrm{P}<0.001$ ). However, despite the high levels of apparent temporal synchronization in the time series of both malaria species, there are important differences in the magnitude and periodicity in the incidence of $P$. falciparum and $P$. vivax malaria when the time series are stratified into geographic regions and provinces as shown below.

\section{Temporal trends of $\mathrm{P}$. falciparum and $\mathrm{P}$. vivax malaria by geographic region}

The weekly number of malaria cases due to $P$. falciparum and $P$. vivax malaria in jungle, mountain and coastal regions are displayed in Figure 3. The annual rates of $P$. falciparum have significantly declined across all geographic regions between 1999 (702.6, 10 and 268.5 cases per 100,000 people in jungle, mountain and coastal regions, respectively) and 2006 (213, 0.2 and 0.9 cases per 100,000 people in jungle, mountain and coastal regions, respectively). On the other hand, the annual rates of $P$. vivax have remained relatively steady in jungle and mountain regions during the last few years of the study period (1283.3 and 96.6 cases per 100,000 people in 2006, respectively) while declining in coastal regions. Overall, $P$. vivax has been the dominant malaria species affecting mountain regions since year 2000, with only brief and small peaks of $P$. falciparum occurrin $g$ in the last few years (Figure 3).

\section{Periodicity and correlation of malaria time series across geographic regions}

Between 1994 and 1998, the incidence of $P$. falciparum in the jungle region was moderately correlated with that in the mountain range region $(\rho=0.52, P<0.0001)$ but not in the coastal region $(\rho=0.07, P=0.28)$. Similarly, the incidence of $P$. falciparum in mountain range areas was only weakly positively correlated with coastal areas $(\rho=$ $0.24, \mathrm{P}<0.0001$ ) during the same period. During 19992006, when P. falciparum incidence started to decline, the incidence of $P$. falciparum in the mountain regions was correlated with that in the coastal areas $(\rho=0.62, P<$
0.0001). In contrast, in the same period the dynamics of $P$. falciparum were weakly negatively correlated in jungle and coastal regions $(\rho=-0.13, P=0.006)$ and uncorrelated between jungle and mountain regions $(\rho=0.008 \mathrm{P}$ $=0.87)$.

Wavelet time series analysis (Figure 4) indicated that in jungle regions, annual and biennial cycles dominate the beginning of the time series of $P$. falciparum infections until about year 2000 when a stronger triennial pattern seems to emerge. In coastal regions, an annual pattern shows the highest power almost continuously. In addition, a strong triennial pattern shows high power during 1998-2002. In mountain regions, the annual pattern shows high power during 1995-1997 and again during 1999-2002. In addition, there is a strong triennial pattern between 1997 and 2002. As shown below the interpretation of these periodic patterns needs to be carried out with caution due to spatial aggregation effects.

For P. vivax (1999-2006), annual cycles show a strong pattern across geographic regions (Figure 5). Mountain regions also show a strong biennial pattern between 2002 and 2005. Moreover, the weekly incidence in the jungle was not correlated with that in the mountain range ( $\rho=$ $0.04, P=0.38$ ) and was weakly negatively correlated with that in the coastal region $(\rho=-0.13, P=0.008)$. Similarly, $P$. vivax incidence in the mountain range region was weakly negatively correlated with that in the coast $(\rho=$ $0.13, \mathrm{P}=0.01$ ) during 1999-2006. These findings are in agreement with the phase lag in the seasonality of $P$. vivax observed in the mountain regions with respect to jungle and coastal regions, as shown in Figure 3.

With regards to synchronization by geographic region, the time series of P. falciparum and P. vivax during 1999-2006 were significantly and positively correlated with each other in coastal $(\rho=0.9, P<0.0001)$ and jungle regions $(\rho=0.76, P<0.0001)$ and slightly correlated in mountain regions $(\rho=0.2, P<0.0001)$ where sharp and brief spikes of $P$. falciparum corresponded to troughs in P. vivax (Figure 3).

\section{Temporal P. falciparum and P. vivax malaria trends and climate at the spatially refined province level}

In order to better understand the factors associated with such seasonality differentials, analyses at a smaller spatial scale were carried out to look for the Provinces in each of the geographic regions where most of the malaria burden in Perú is located. The association between malaria incidence and climatological variables (mean temperature, minimum temperature, maximum temperature and precipitation) was also analysed for those 28 provinces for which weekly climatological data were available. 

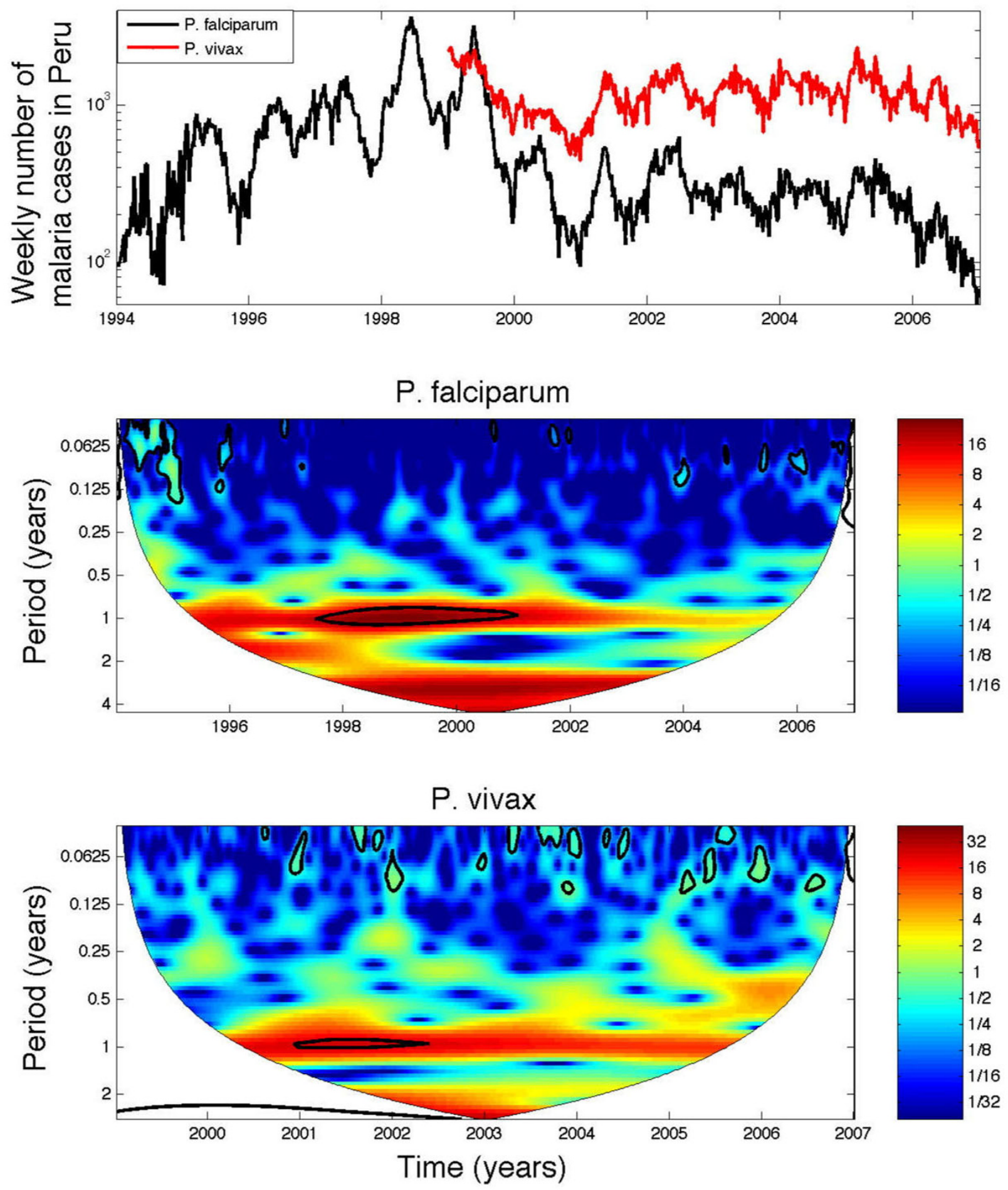

Figure 2

The weekly time series of the number of Plasmodium falciparum (1994-2006) and P. vivax (1999-2006) in Perú during the period 1994-2006 (in logarithmic scale) and the corresponding wavelet power spectrum for both malaria time series. For both time series, annual cycles have the highest power. There is also a strong triennial pattern for the $P$. falciparum series during 1998-2003 and a strong biennial cycle for $P$. vivax during 2002-2004. 

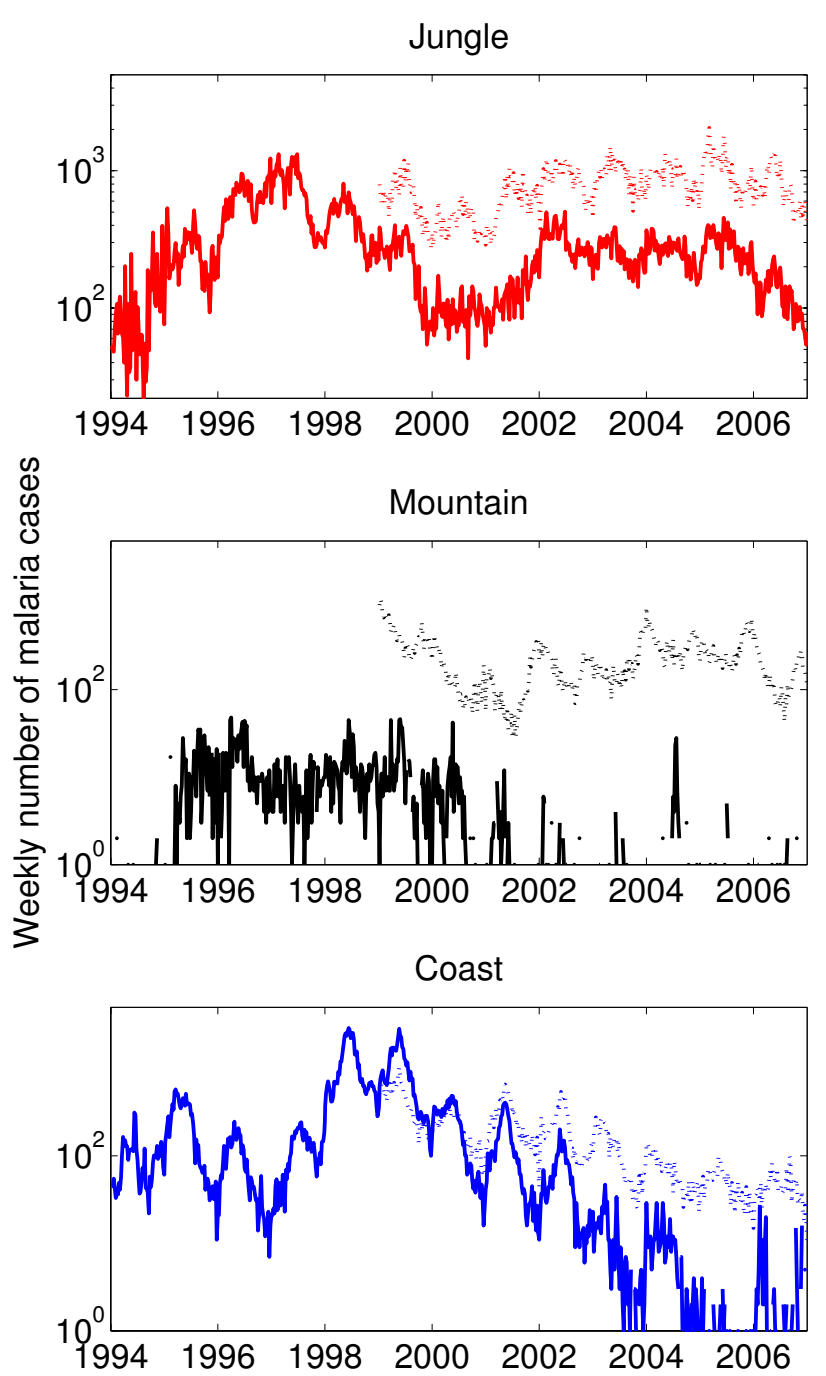

Figure 3

The weekly number of cases due to Plasmodium falciparum (solid line) and $P$. vivax (dotted line) in Perú stratified by geographic region (jungle, mountain range, coast) during the period 1994-2006 (notification of $\boldsymbol{P}$. vivax did not start until 1999). A decline in the number of malaria cases due to $P$. falciparum in the mountain and coastal areas can be observed in the last few years while $P$. vivax has only been declining in coastal regions in the last few years.

\section{Jungle regions}

The weekly malaria counts, due to $P$. falciparum and $P$. vivax, for the provinces with the highest malaria burden in jungle regions are shown in (Additional file 2 and Additional file 3), respectively. A map highlighting these provinces is given in Additional file 4. It can be seen that while $P$. falciparum is most concentrated in the northern part of the jungle, $P$. vivax extends from the northern to the southern jungle region. $P$. falciparum and $P$. vivax incidences are significantly correlated in Alto Amazonas (Spearman $\rho=0.65, \mathrm{P}<0.0001)$, Datem del Marañón $(\rho$ $=0.71, \mathrm{P}<0.0001)$, Mariscal de Caceres $(\rho=0.80, \mathrm{P}<$ $0.0001)$ and San Martin $(\rho=0.70, P<0.0001)$. By inspection of the wavelet power spectrum at the province level, the periodicity of $P$. falciparum cases was found to be dominated by a triennial pattern to which the provinces of Alto Amazonas, Jaen, Mariscal de Caceres, and San Ignacio contribute the most (Additional file 5). Moreover, a switch from an annual to a biennial pattern in 1997 and then to a triennial pattern about 2000 can be observed in the province of Datem del Marañón. Similar changes in periodicity can be observed in the provinces of Loreto, Jaen, Utcubamba and San Ignacio. By contrast, the dynamics of $P$. vivax in jungle regions are dominated by annual cycles particularly by the province of Alto Amazonas.

In jungle regions, P. falciparum incidence was weakly correlated with precipitation in the province of Atalaya (Spearman $\rho=0.18, P<0.0001$ ). Similarly, the correlation between $P$. vivax and precipitation was weak in the province of Alto Amazonas (Spearman $\rho=0.15, \mathrm{P}<$ $0.0013)$. Mean temperature in the province of San Martin was weakly correlated with $\mathrm{P}$. falciparum $(0.19, \mathrm{P}<$ $0.0001)$ and $P$. vivax $(0.34, P<0.0001)$. Additional files 6 and 7 show the weekly time series of climatological variables and P. falciparum and P. vivax incidence in the Province of Alto Amazonas located in the jungle region.

\section{Coastal regions}

Plasmodium vivax is the dominant species in coastal areas (Additional file 4) and is highly localized in the northern coastal region. Plasmodium falciparum and $P$. vivax are highly synchronized in Ayabaca (Spearman $\rho=0.88, \mathrm{P}<$ $0.0001)$, Sechura $(\rho=0.68, P<0.0001)$, Paita $(\rho=0.86, P$ $<0.0001)$, Zarumilla $(\rho=0.72, \mathrm{P}<0.0001)$, Contralmirante Villar $(\rho=0.75, P<0.0001)$, and Huancabamba $(\rho$ $=0.76, P<0.0001)$. The dynamics of $P$. falciparum in coastal regions are dominated by concurrent annual and triennial cycles, primarily observed in the provinces of Ayabaca, Sechura, Paita, and Zarumilla. Simpler dynamics are observed for $P$. vivax with dominant annual cycles across provinces except for a few provinces with concurrent annual and biennial cycles including Zarumilla, Lambayeque, and Ferreñafe.

Incidence in coastal areas was more closely correlated with precipitation than in jungle areas. $P$. falciparum incidence was significantly correlated with precipitation in the provinces of Chiclayo (Spearman $\rho=0.54, \mathrm{P}<$ $0.0001)$, Ayabaca $(\rho=0.42, P<0.0001)$ and Contralmirante Villar $(\rho=0.34, P<0.0001)$. P. vivax incidence was correlated with precipitation with similar correlation coef- 

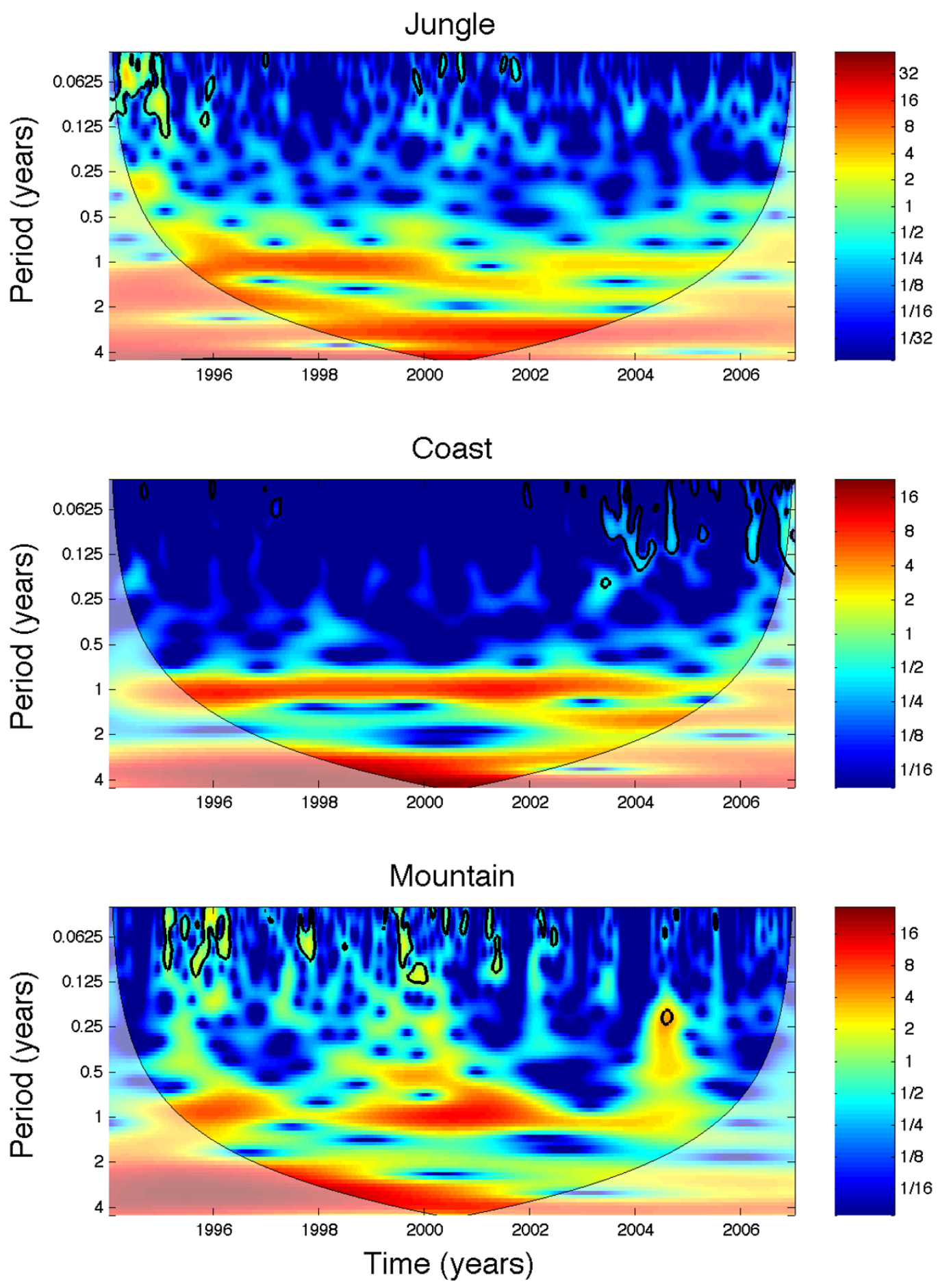

Figure 4

The wavelet power spectrum of the weekly series of $P$. falciparum (1994-2006) stratified by geographic region. In jungle regions, annual and biennial cycles dominate the beginning of the time series until about 2000 when a triennial pattern starts to show the highest power. An annual pattern in coastal regions shows almost continuously the highest power. In addition, a strong triennial pattern shows high power during 1998-2002. In mountain regions, the annual pattern shows high power during 1995-1997 and then again during 1999-2002. In addition, between 1997 and 2002 a strong triennial pattern shows high power. 

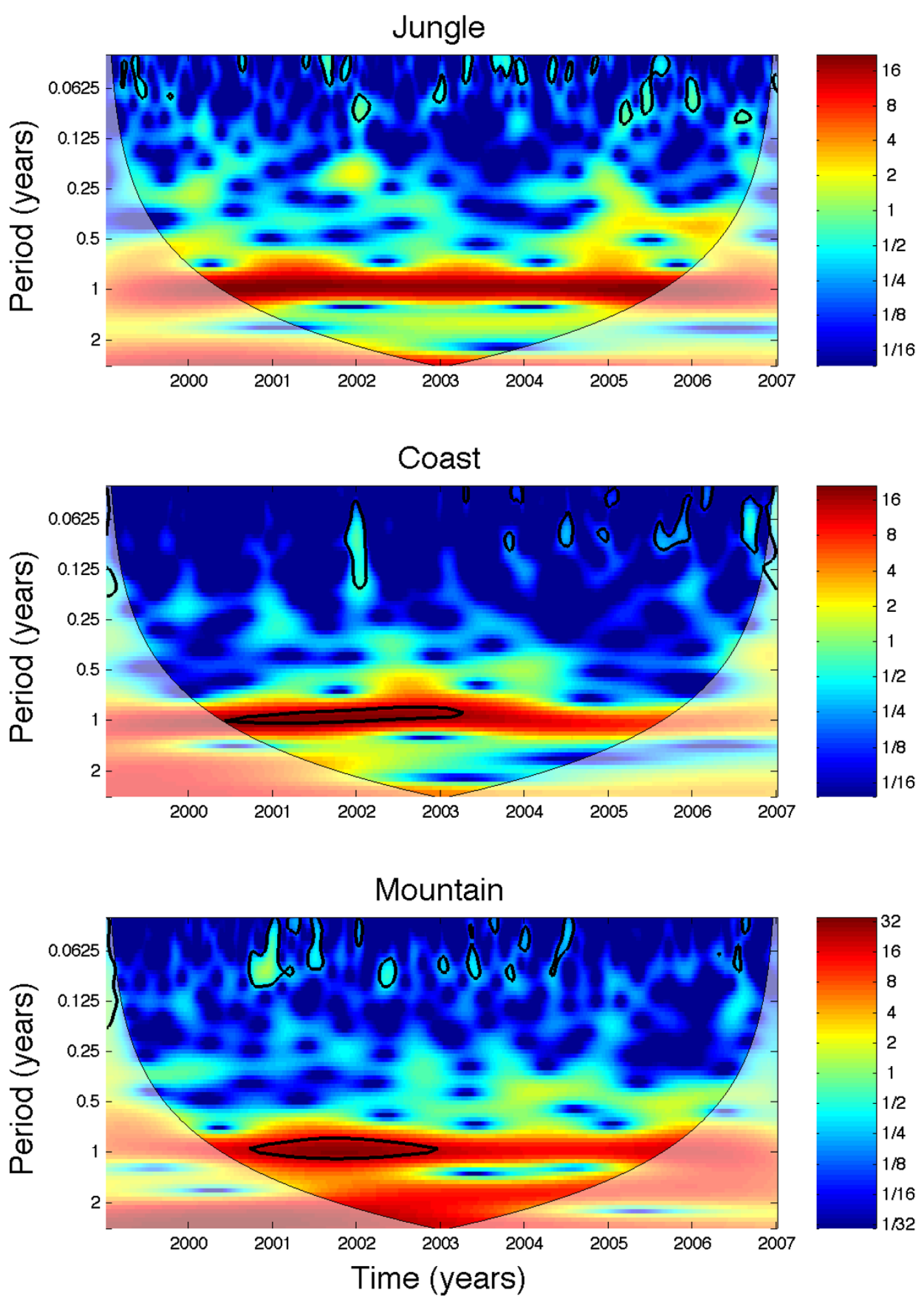

\section{Figure 5}

The wavelet power spectrum of the time series of $P$. vivax (1999-2006) stratified by geographic region. Annual cycles show a strong pattern for the three geographic regions. In addition, there is a strong biennial pattern between 2002 and 2005 in mountain regions. 
ficients $(\rho=0.32-0.48(\mathrm{P}<0.0001)$. Furthermore, both species time series were slightly correlated with temperature variables. For example, the association with minimum temperature was highest in the province of Ascope with a correlation coefficient of $0.35(\mathrm{P}<0.0001)$.

\section{Mountain regions}

The malaria burden in mountain regions has become dominated by $P$. vivax as can be seen in Figure 3. Interestingly, while $P$. falciparum is most concentrated in the northern mountain region, $P$. vivax is more concentrated in the central mountain region (Additional file 4). Moreover, $P$. vivax incidence in mountain regions has reached endemic levels with high degree of seasonality. Wavelet time series analysis on the weekly malaria time series of the 10 provinces with the highest malaria burden in mountain regions confirms the strong annual pattern observed in the analysis using aggregated time series of mountain regions, but biennial cycles, which were identified in the wavelet power spectrum using the aggregated data for mountain regions, are strong only in a few of the provinces during 2002-2004 (Additional file 8). This highlights one of the effects associated with data aggregation. This issue is described in detail in the Discussion.

There is a scarcity of climate data in the mountain regions. Moreover, the incidence of $P$. falciparum in mountain regions has been in decline in the last few years. By contrast, the dominating $P$. vivax malaria species in mountain regions was correlated with precipitation in the provinces of Cangallo (Spearman $\rho=0.25, \mathrm{P}<0.0001$ ), Acomayo ( $\rho$ $=0.47, \mathrm{P}<0.0001)$ and Lauricocha $(\rho=0.46, \mathrm{P}<0.0001)$. $P$. vivax malaria incidence was moderately correlated with temperature variables $(\rho=0.29-0.47, \mathrm{P}<0.0001)$.

\section{Phase lag in periodic patterns}

The role played by climatological variables in contributing to the phase lag in the pattern of $P$. vivax malaria in mountain regions with respect to $P$. vivax malaria in jungle and coastal regions was assessed (Figure 3). Figure 6 shows the time series of $P$. vivax cases in three Peruvian provinces that are representative of jungle, coast and mountain regions along with their corresponding wavelet power spectrum that highlights the strong annual pattern in all three provinces.

The dynamics of $P$. vivax in the province of La Convencion (mountain) follows a reciprocal seasonality pattern to that observed in Alto Amazonas (jungle) and (Ayabaca) coastal regions. A comparison of temperature and precipitation temporal trends and malaria cases due to P. vivax is shown in Figure 7. A lagged cross-correlation analysis indicates that climatological variables are associated with the out-phase pattern observed in mountain regions. The clearest picture was obtained from the province of Aya- baca (coast) where the climate seasonal cycle is clearly ahead of that in the mountain regions (Figure 8). Additional file 9 shows the highest correlation between precipitation and minimum temperature in the province of Acomayo (mountain) followed by Ayabaca (coast) and Alto Amazonas (jungle).

\section{Critical community size}

While reports of $P$. falciparum were found in all the weeks during $1999-2006$ in jungle regions, only $86.5 \%$ and $39.4 \%$ of the weekly time series showed $P$. falciparum reports in coastal and mountain regions, respectively. $P$. vivax is more persistent than $P$. falciparum reported in $100 \%$ of the weeks with malaria reports during 19992006 in jungle, mountain and coastal regions.

Similar persistence patterns for both $P$. falciparum and $P$. vivax malaria in jungle regions were found at the province level as measured by negative correlations between population size and the proportions of weeks in the time series with no reported malaria during the period 1999-2006 (for P. falciparum: Spearman $\rho=-0.57, \mathrm{P}=0.002$; for $P$. vivax: Spearman $\rho=-0.48, P=0.01$, Figure 9). In addition, findings also indicated a weak but significant pattern of persistence as a function of population size for $P$. vivax in mountain regions (Spearman $\rho=-0.34, P=0.003$ ), but this pattern was not significant for $P$. falciparum. There was no significant correlation in coastal regions between population size and the proportion of weeks with no reported malaria due to $P$. falciparum or $P$. vivax.

\section{Spatial heterogeneity}

During the period 1994-1998, the spatial heterogeneity of malaria at the province level (as measured by the Gini index) due to $P$. falciparum was highest in coastal regions $(0.88)$ followed by mountain (0.73) and jungle regions (0.57). During 1999-2006, spatial heterogeneity for $P$. falciparum was similar across geographic regions with the corresponding Gini indices being 0.68, 0.73, and 0.69 in jungle, coastal and mountain areas, respectively. That is, the Gini index "converged" from 0.88/0.73/0.57 to $0.73 /$ $0.69 / 0.68$ in coastal, mountain and jungle areas. Spatial heterogeneity for $P$. vivax in jungle regions was similar to that of $P$. falciparum during the same period (0.6) and slightly higher in mountain and coastal areas (0.89 and 0.87 , respectively). Figure 10 shows the corresponding Lorenz curves by geographic region for the common period 1999-2006.

\section{Discussion}

Although a few studies have explored spatio-temporal patterns of malaria in regions such as Thailand [27], and global maps of malaria risk have started to be generated [28] to the best of knowledge this is the first study to assess the spatial and temporal dynamics of malaria using 

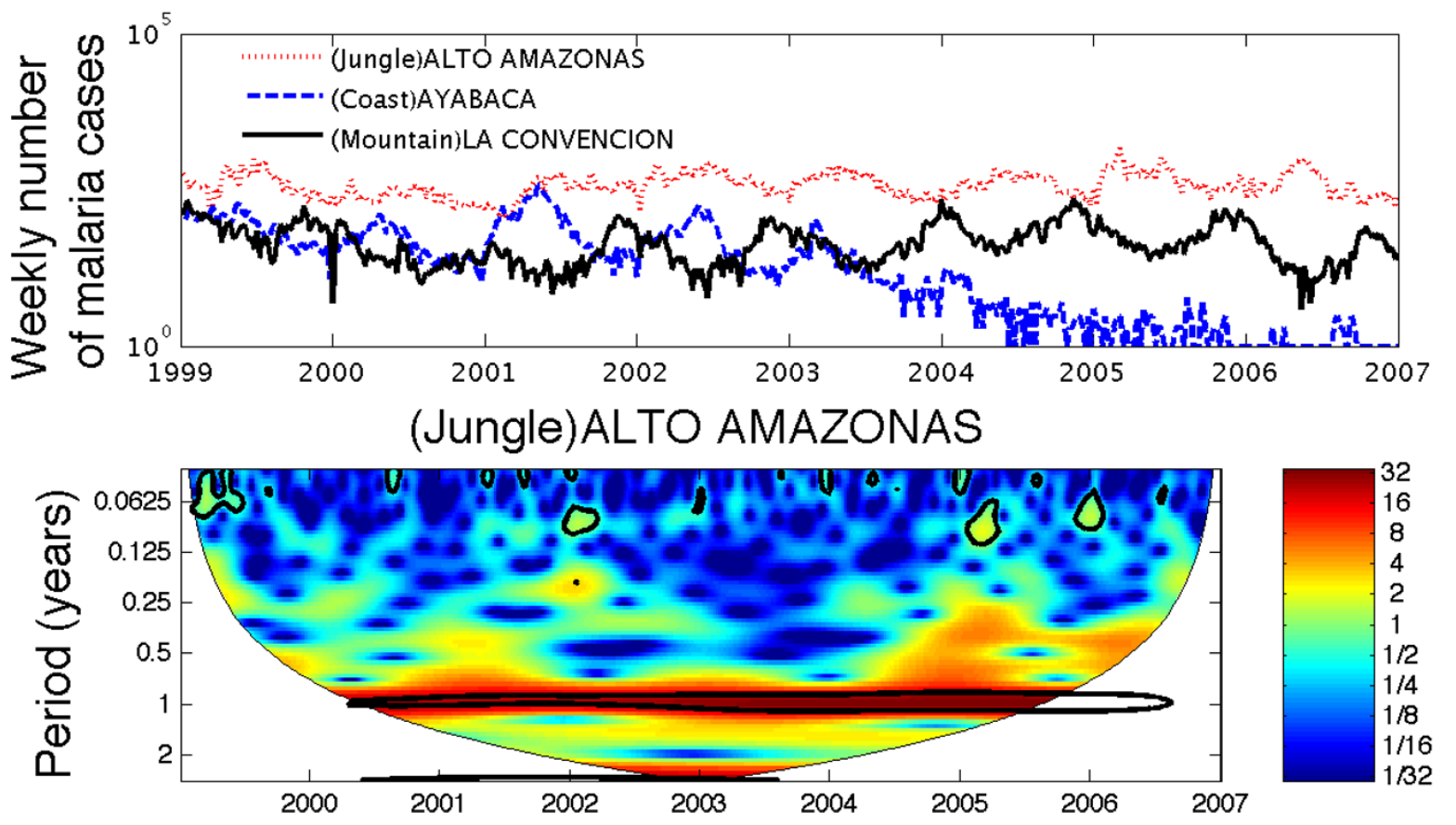

(Coast)AYABACA
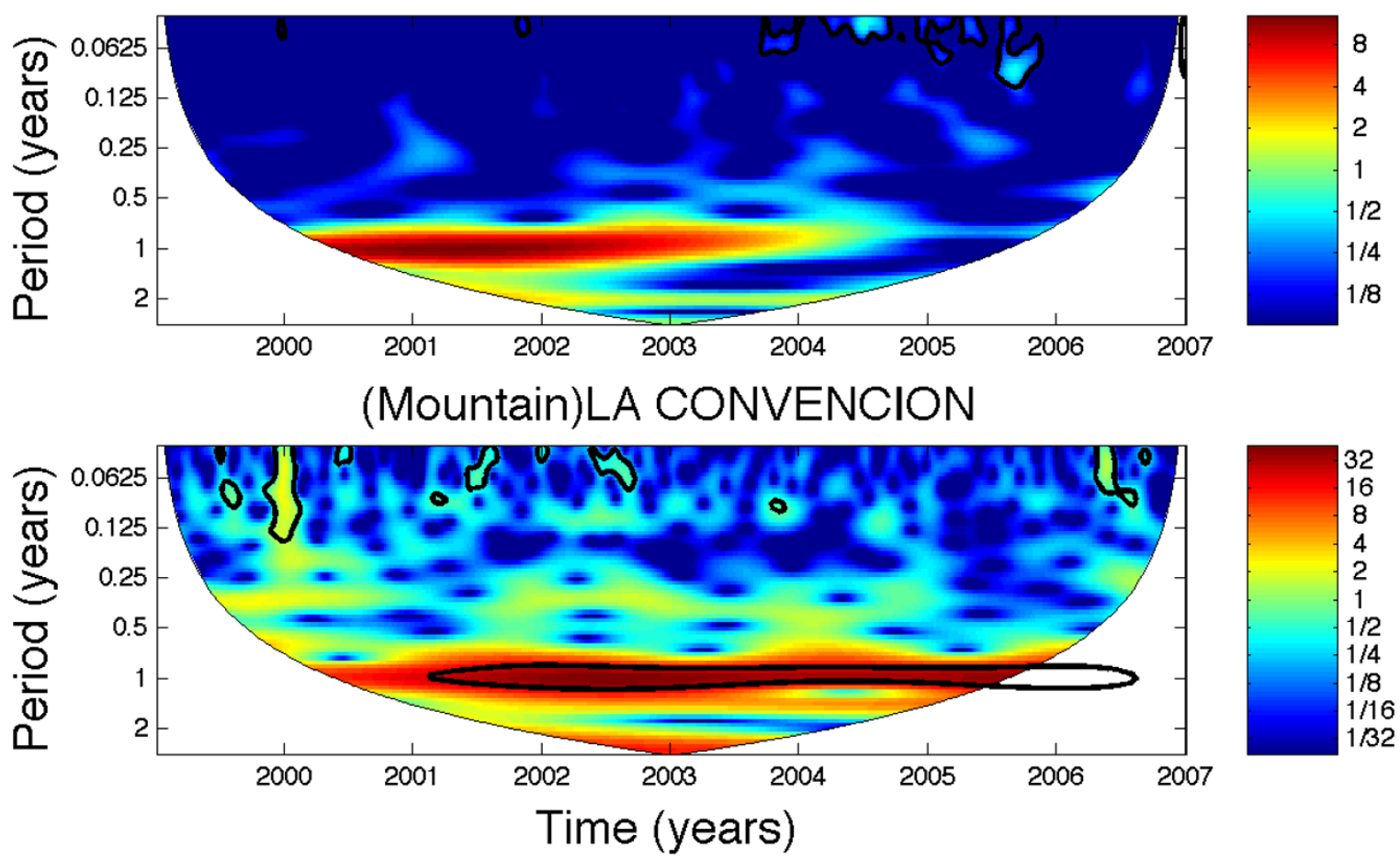

Figure 6

The weekly numbers of malaria cases due to $P$. vivax in three Peruvian provinces that are representative of jungle, coast and mountain regions along with their corresponding wavelet power spectrum. The annual pattern shows the highest power across geographic regions. While the time series of $P$. vivax in the jungle and coastal provinces follow a similar seasonality pattern, there is a phase lag in the seasonality $P$. vivax incidence in the province of La Convencion, which is representative of mountain regions. 

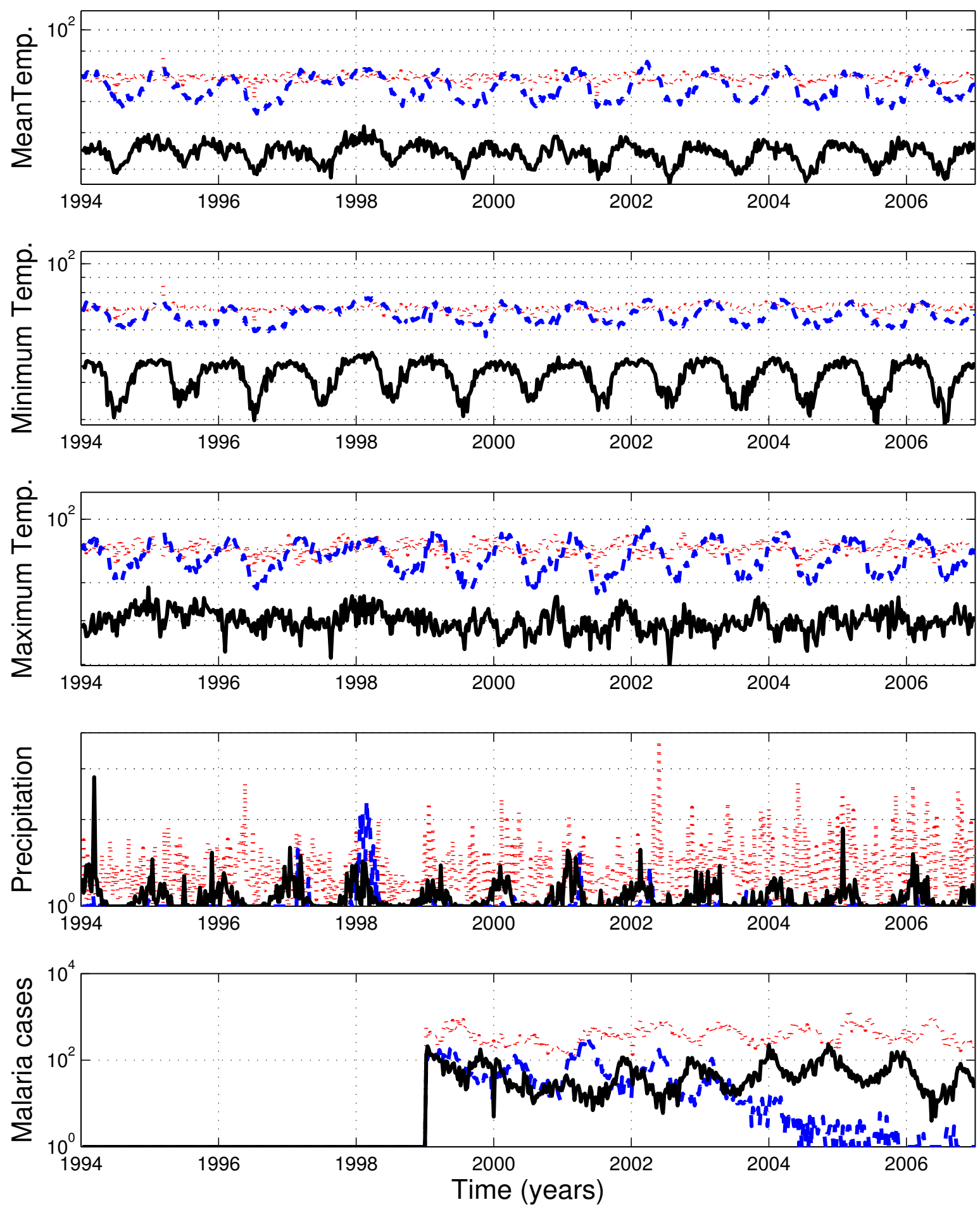

\section{Figure 7}

Comparison of temperature and precipitation temporal trends and malaria cases due to $P$. vivax in three Peruvian provinces that are representative of jungle (red dotted line), coast (blue dashed line) and mountain (black solid line) regions. The phase lag in the seasonality pattern in the Province of La Convencion, which is representative of mountain regions, with respect to the seasonality of the coastal and jungle provinces can be explained by climatological variables. 

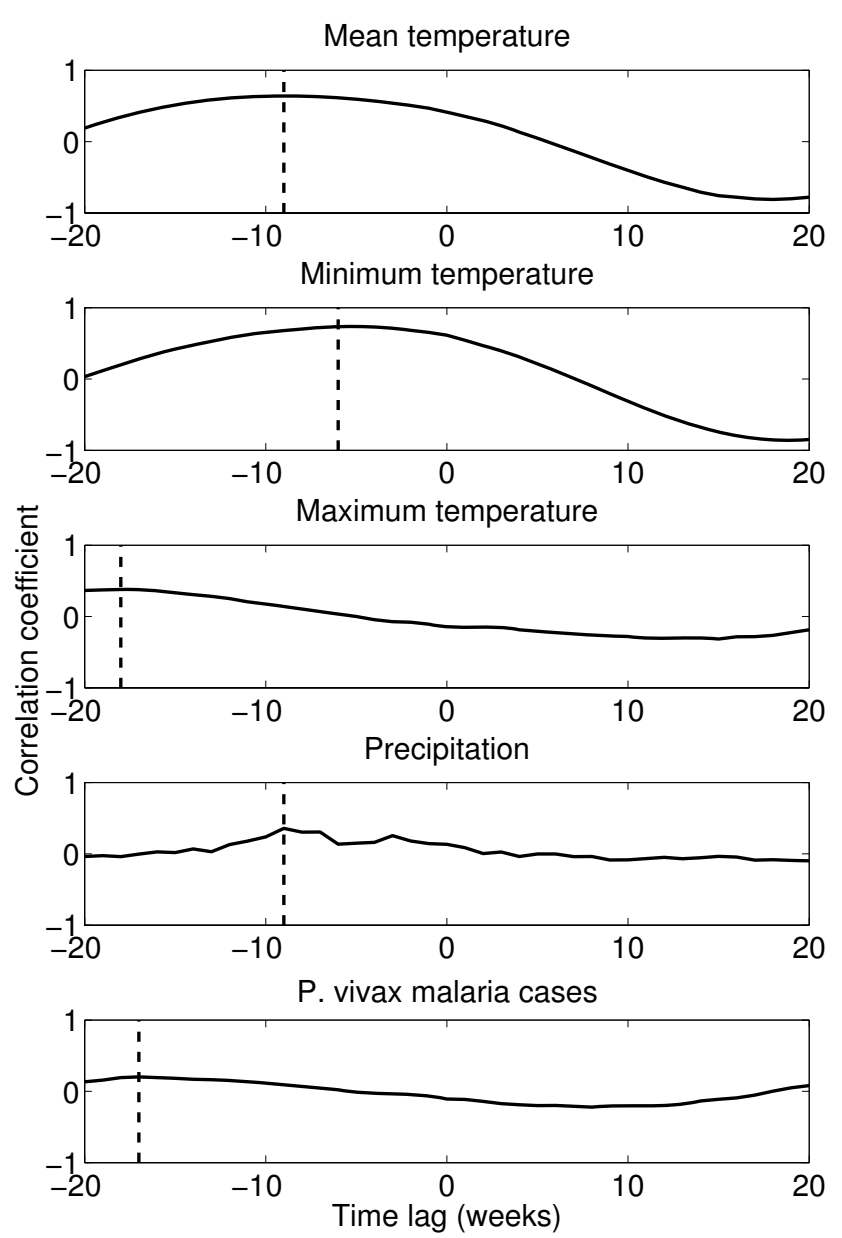

Figure 8

Lagged cross-correlation plots of the climatological variables and $P$. vivax malaria incidence in the province of Ayabaca (coast) and the province of La Convencion (mountain) using the climatological data from the neighboring province of Acomayo as a proxy for the climate data for the province of La Provincia. The dashed line indicates the temporal lag associated to the maximum correlation coefficient.

high-resolution spatio-temporal data of $P$. falciparum and P. vivax malaria infections in South America.

Despite the declining trend of $P$. falciparum, both $P$. falciparum and $P$. vivax weekly counts were found to be strongly correlated in jungle and coastal areas and weakly correlated in mountain regions where $P$. falciparum infections have become rare in the last few years. However, in those regions sharp and brief spikes of $P$. falciparum infections concur with troughs of $P$. vivax malaria. In contrast, the time series of $P$. falciparum and $P$. vivax malaria at the national level were only moderately correlated. This highlights the importance of high-resolution spatio-temporal data to detect heterogeneity in malaria incidence and periodicity patterns.
While analysis of temporal malaria trends of $P$. vivax malaria at the aggregated national level are quite consistent with the corresponding analyses by geographic region or province level (strong annual pattern followed by biennial cycles), results indicate more irregular periodicity patterns for $P$. falciparum where biennial and triennial cycles have emerged in the more recent years of the study period, probably due to its significant decline, particularly in mountain and coastal regions. This highlights the role of spatial scales in the periodicity of malaria incidence [29]. Two types of problems derived from using aggregated data were identified. First, dominant periodic patterns could differ across spatial units (e.g., provinces). For example, in this study, wavelet time series analysis identified a single dominant triennial pattern due to $P$. falciparum in the jungle provinces of Alto Amazonas, Jaen, Mariscal de Caceres, and San Ignacio, but this is not the characteristic pattern observed from the jungle-region-level wavelet time series analysis. Thus, apparent changes could be detected in periodicity over time in jungle regions while ignoring true local differences in periodicity at the province level (Figure 4). These differences in periodicity at different spatial scales could be associated with variations in the environmental landscape such as floods in the highly heterogeneous network of rivers and lakes [3,30,31]. Furthermore, the aggregated data for $P$. vivax in coastal regions indicate a continuously strong annual pattern, whereas wavelet spectral analysis at the province level reveals a few provinces with concurrent annual and biennial cycles including Zarumilla, Lambayeque, and Ferreñafe. Another complication in understanding of the spatio-temporal processes involved in malaria transmission arises when incidence in two or more localities are phase lagged with respect to each other. In Perú, the time series of malaria due to $P$. vivax in mountain regions were found to be significantly phase lagged (about 180 degrees) with respect to coast and jungle areas. Importantly, this pattern could not have been deciphered from the time series aggregated at the national level alone. In regards to phase lags in the incidence of malaria, a similar pattern has been reported for the archipelago of Vanuatu where P. falciparum malaria was found to be predominant in the long wet season and $P$. vivax malaria was predominant in the dry season [32,33]. Although the best climatological data at the province level available for Perú were used, these results need to be interpreted with caution. Climatological data from meteorological stations may not be necessarily representative for the larger provinces and the station coverage in the mountain regions was limited. The use of interpolated data with better meteorological station coverage at smaller spatial scales (e.g., district level) is recommended.

Understanding variability in the temporal dynamic of malaria epidemics has public health implications. For example, a number of studies have explored the roles of exogenous (e.g., climate) and endogenous (e.g., intrinsic 

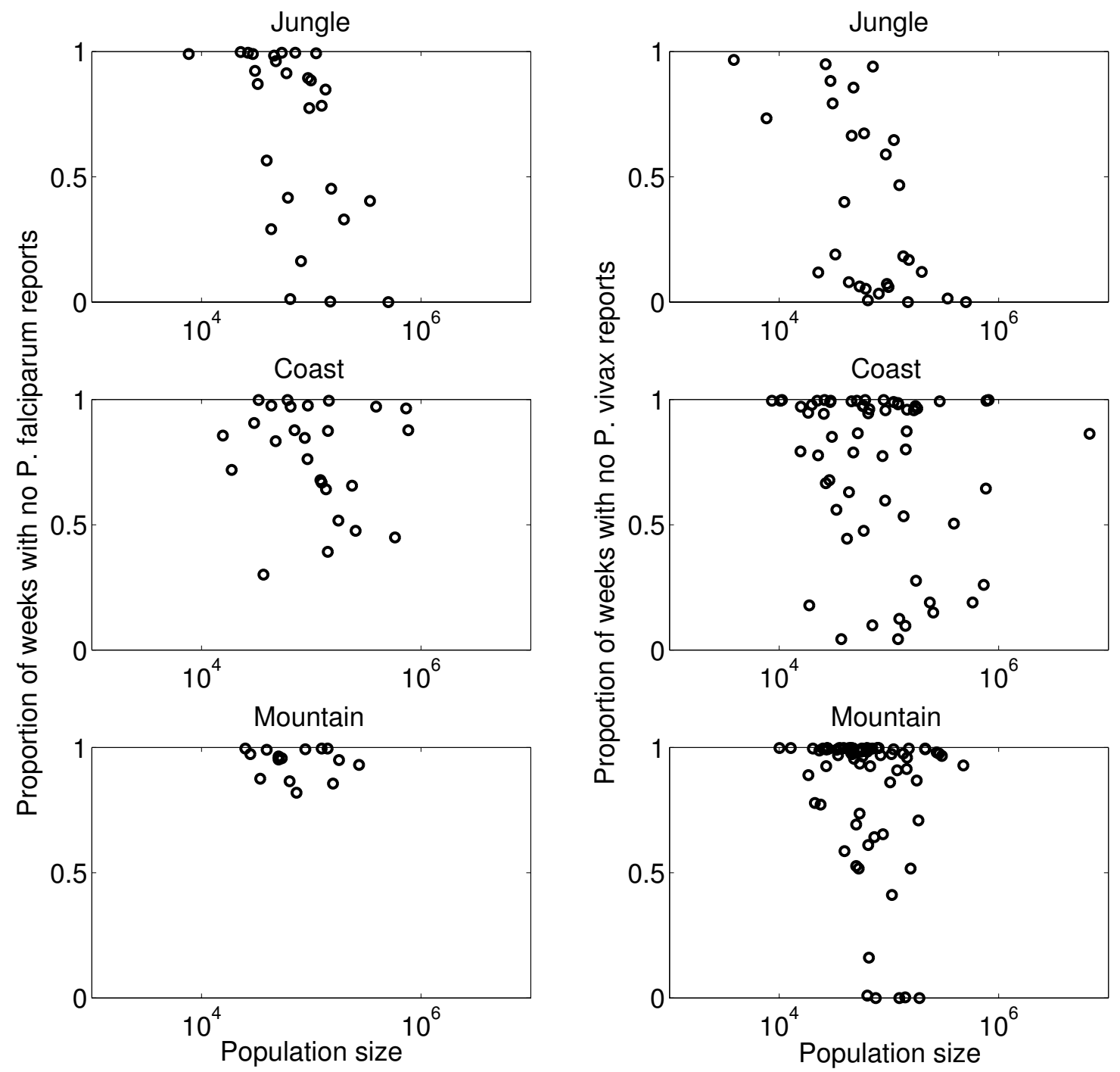

\section{Figure 9}

The proportion of weeks with no malaria reports as a function of population size of the Peruvian provinces classified in coastal, mountain, and jungle areas. The proportion of weeks with no malaria reports was negatively correlated with population size in jungle areas for both $P$. falciparum (Spearman $\rho=-0.59, P=0.00 I)$ and $P$. vivax $($ Spearman $\rho=$ $0.59, P=0.00 \mathrm{I})$ and in mountain regions for $P$. vivax only (Spearman $\rho=-0.34, P=0.003$ ) during $1999-2006$.

to the transmission dynamics) factors in this variability using monthly data from East Africa [34-36]. The current understanding is that rainfall and temperature play an important role in cycles of low periodicity, while endogenous dynamics of malaria may explain cycles of longer periodicity [23]. The findings of this study indicate moderate levels of correlation between malaria incidence and precipitation in coastal areas; however, this correlation was weak in jungle areas. The lower correlation in jungle areas could be explained by significant heterogeneity in the dynamics of breeding sites due to the presence of flooding of the surroundings of the highly heterogeneous river networks and lakes $[3,30,31]$ and population mobility patterns. For example, anecdotal evidence by one of the team members $(\mathrm{CM})$ suggests that outbreaks of malaria infections in northern jungle regions of Perú are associated with movement patterns of timber merchants who enter the jungle at low river levels and exit when river levels rise. In fact, a study has found that the daily Nanay river level in Iquitos, Perú to explain $28 \%$ of the variability 

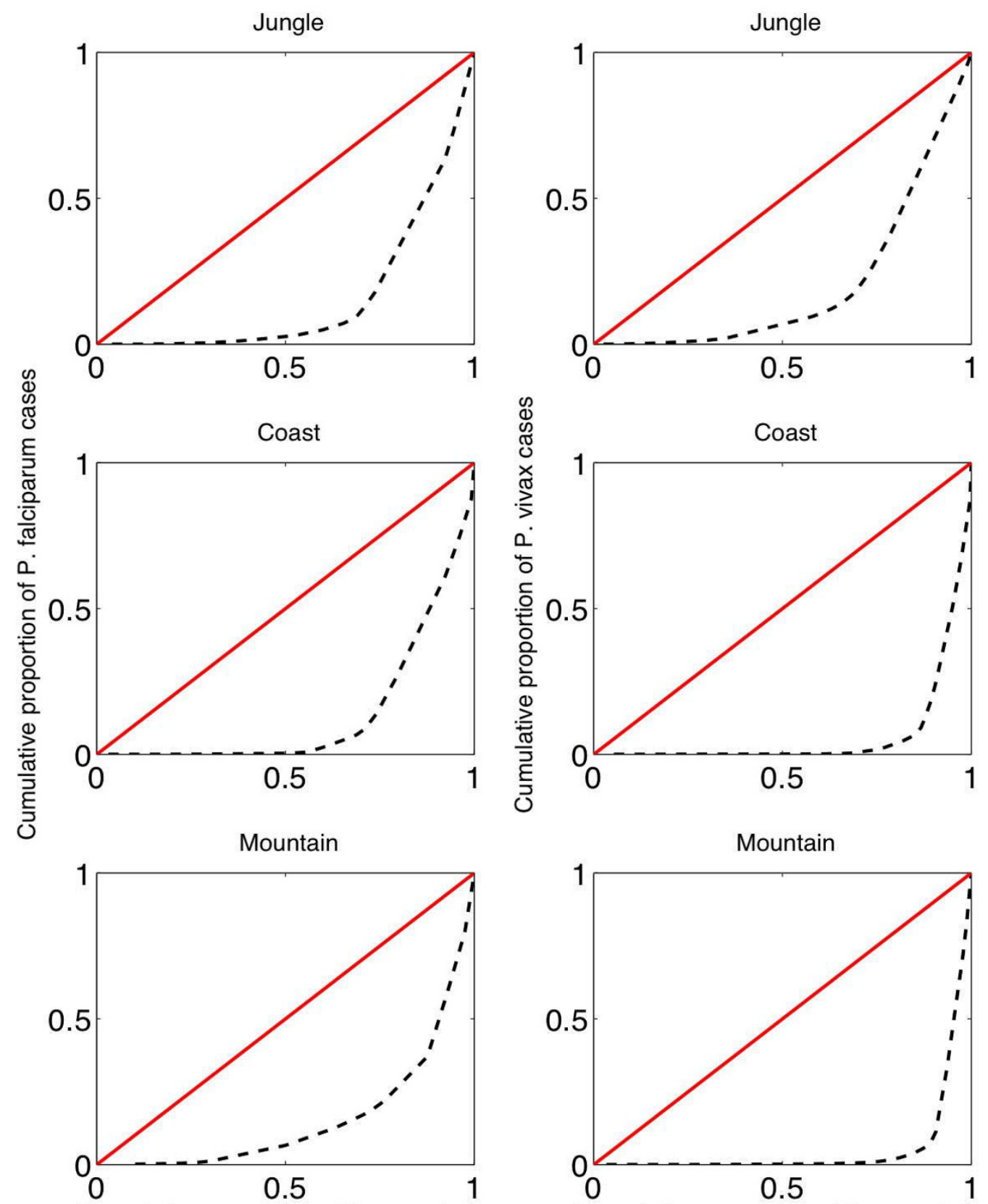

Cumulative proportion of the population

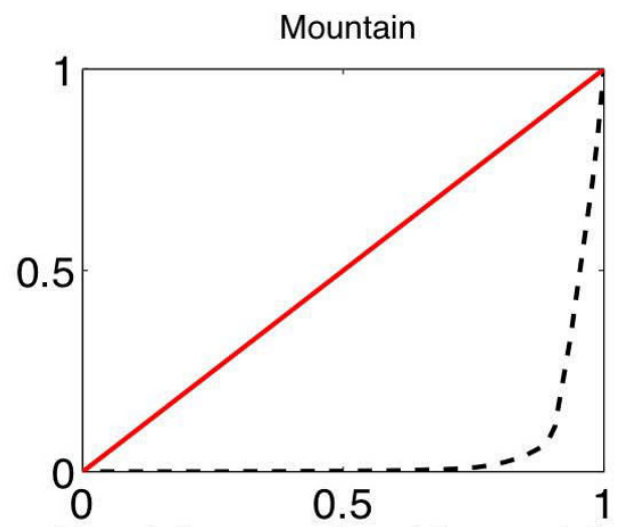

Cumulative proportion of the population

Figure 10

The Lorenz curves of the distribution of the total number of malaria case notifications for $P$. falciparum and $P$. vivax as a function of population size at the province level during 1999-2006. The red solid line (first diagonal) represents a constant distribution of malaria case notifications (no heterogeneity). During 1999-2006, spatial heterogeneity for $P$. falciparum was similar across geographic regions with the corresponding Gini indices being $0.68,0.73$, and 0.69 in jungle, coastal and mountain areas, respectively. Spatial heterogeneity for $P$. vivax in jungle regions was similar to that of $P$. falciparum during the same period $(0.6)$ and slightly higher in mountain and coastal areas ( 0.89 and 0.87 , respectively). 
in total malaria risk [30,3]. Similarly, other activities associated with malaria infection risk are the gold mining industry in the Southern jungle areas confined mainly to the beaches of the Inambari and Madre de Dios rivers, and rice production in the northern coastal areas of Perú due to inappropriate cleaning of the irrigation systems [37].

The decline in the incidence of $P$. falciparum is encouraging, but it needs to be interpreted with caution as it could be associated with multiple factors including methodological (e.g., associated with microscopy-based identification of malaria species [38-40]), treatment interventions $[41,42]$ and cross-protective immunity [43]. Traditional microscopy-based detection techniques have significant limitations by failing to detect the presence of low-level and mixed infections $[38,39,44]$. In fact, literature reviews have concluded that in general fewer mixed species $P$. falciparum/P. vivax infections are observed than would be expected from the prevalence of constituent malaria species, which is in agreement with this study $[45,46,43]$. Longitudinal field studies [47-50] and clinical studies (e.g., [50]) suggest that in mixed-species malaria infections in humans one of the constituent Plasmodium species tends to dominate. Nevertheless, the consistent and gradual decline of the incidence of $P$. falciparum across geographic regions puts more weight into the role of their biological differences leading to different treatment interventions and cross-protective immunity.

Unlike $P$. falciparum infections, a significant fraction of $P$. vivax cases relapse following treatment due to the difficulty in completely eradicating dormant liver stages of the parasite (the hypnozoites), those stages are targeted by Primaquine. Hence, P. vivax incidence could be affected by relapses of previously infected individuals [51]. While the P. vivax treatment guidelines have not had significant changes for almost 50 years (with first-line therapies, Chloroquine+Primaquine, unchanged for 50 years) [52], there have been changes in malaria treatment policies for $P$. falciparum driven primarily by the appearance of drug resistance [53], such changes may have affected the observed incidence of $P$. falciparum. Indeed, the spike of falciparum malaria in the 90's has been explained in part by the use of ineffective drugs.

In addition, the role of cross-protective immunity whereby prior exposure to $P$. vivax infection ameliorates the course of a subsequent $P$. falciparum infection could also contribute to the substantial reduction of $P$. falciparum infections [31,54]. Hence, further work that includes longitudinal studies that make use of accurate detection methods $[55,56]$ across geographic regions of Perú are needed to quantify the impact of pharmaceutical interventions and cross-protection immunity against malaria. Further insights into the dynamics and impact of interventions can be gained through the use of mathematical models [57].

Important differences in the dynamic of $P$. falciparum and $P$. vivax were found in Perú beyond the fact that $P$. vivax is more widespread in Perú than P. falciparum. Of note, community size was also found to be significantly associated with malaria persistence due to both malaria species in jungle regions but not in coast and mountain regions, which is in agreement with dengue persistence in Perú [58]. Hence, this highlights the need to evaluate the impact of malaria control programmes in jungle areas and the potential benefits from the use of bed nets as a means of reducing the "effective community size" in areas where malaria persistence is highest. It is worth pointing out that the authors have made use of the best, most complete data available, and while of course it is not ideal, it is reassuring that the patterns of persistence as a function of community size are quite clear in jungle areas which are the most remote and difficult to access in Perú.

Findings indicated significant spatial heterogeneity due to P. falciparum (1999-2006) with similar levels across geographic regions (Gini 0.7), which could suggest important differences in levels of control of $P$. falciparum in all geographic regions. Similarly, spatial heterogeneity associated to $P$. vivax was higher in coastal $(0.87)$ and mountain $(0.89)$ regions while heterogeneity in jungle regions $(0.6)$ was similar to that of $P$. falciparum infections, indicating less variability in the activity of $P$. vivax in jungle than in coastal or mountain regions. For comparison, spatial heterogeneity of dengue fever (1994-2006) in Perú has been reported to be higher in coastal areas (Gini $0.59)$, followed by mountain (0.36) and jungle areas (0.27) [58].

\section{Conclusion}

Overall, this study highlights the importance of highly refined spatial and temporal data of malaria incidence together with demographic and geographic information in improving the understanding of malaria persistence due to multiple malaria species in human populations, the impact of pharmaceutical interventions, detection of heterogeneity, and generation of hypotheses.

\section{Competing interests}

The authors declare that they have no competing interests.

\section{Authors' contributions}

GC conceived the study, analysed the data and wrote the first draft of the manuscript. CM, AE and FEM participated in the interpretation of results and in the writing and editing of the manuscript. 


\section{Additional material}

\section{Additional file 1}

Distribution of population density across coastal, mountain and jungle areas in Perú. Boxplot of the distribution of population density in coastal, mountain, and jungle areas. The population density ranged from a median of 22.3 people $/ \mathrm{km}^{2}$ in the mountain range, 12.38 in the jungle areas, and 172 in the coastal areas.

Click here for file

[http://www.biomedcentral.com/content/supplementary/14752875-8-142-S1.jpeg]

\section{Additional file 2}

The weekly malaria counts for the provinces with the highest $\mathrm{P}$. falciparum malaria burden in jungle regions. The weekly malaria counts for the provinces with the highest $\mathrm{P}$. vivax malaria burden in jungle regions. $\mathrm{P}$. falciparum and $\mathrm{P}$. vivax incidence is significantly correlated in Alto Amazonas (Spearman rho $=0.65, P<0.0001$ ), Datem del Marañón (rho $=0.71, P<0.0001$ ), Mariscal de Caceres ( $r$ ho $=0.80, P$ $<0.0001)$ and San Martin (rho =0.70, $P<0.0001)$. Case notification of P. vivax did not start until 1999.

Click here for file

[http://www.biomedcentral.com/content/supplementary/14752875-8-142-S2.jpeg]

\section{Additional file 3}

The weekly malaria counts for the provinces with the highest $P$. vivax malaria burden in jungle regions. The weekly malaria counts for the provinces with the highest $\mathrm{P}$. vivax malaria burden in jungle regions. P. falciparum and $\mathrm{P}$. vivax incidence is significantly correlated in Alto Amazonas (Spearman rho $=0.65, P<0.0001$ ), Datem del Marañón $($ rho $=0.71, P<0.0001)$, Mariscal de Caceres $(r h o=0.80, P<0.0001)$ and San Martin (rho $=0.70, P<0.0001$ ). Case notification of $\mathrm{P}$. vivax did not start until 1999.

Click here for file

[http://www.biomedcentral.com/content/supplementary/14752875-8-142-S3.jpeg]

\section{Additional file 4}

Distribution of P. falciparum and P. vivax across geographic regions in Perú. The ten provinces with the highest malaria burden due to P. falciparum and $\mathrm{P}$. vivax are highlighted with red squares (jungle), triangles (mountain) and circles (coast). Black dots indicate the centroides (latitude, longitude coordinates) of each of the 195 provinces comprising jungle, coastal and mountain regions.

Click here for file

[http://www.biomedcentral.com/content/supplementary/1475-

2875-8-142-S4.jpeg]

\section{Additional file 5}

Wavelet power spectrum of $\mathrm{P}$. falciparum time series in jungle regions. The wavelet power spectrum of the time series of $\mathrm{P}$. falciparum (1994-2006) for the provinces with the highest P. falciparum malaria burden in jungle regions.

Click here for file

[http://www.biomedcentral.com/content/supplementary/14752875-8-142-S5.jpeg]

\section{Additional file 6}

Weekly time series of $P$. falciparum malaria and climatological variables in the province of Alto Amazonas. The weekly time series of four climatological variables: mean temperature $\left({ }^{\circ} \mathrm{F}\right)$, minimum temperature $\left({ }^{\circ} \mathrm{F}\right)$, maximum temperature $\left({ }^{\circ} \mathrm{F}\right)$, precipitation (in) and $\mathrm{P}$. falciparum malaria incidence in the province of Alto Amazonas, which is located in the jungle, during 1994-2006.

Click here for file

[http://www.biomedcentral.com/content/supplementary/14752875-8-142-S6.jpeg]

\section{Additional file 7}

Weekly time series of $\mathrm{P}$. vivax malaria and climatological variables in the province of Alto Amazonas. The weekly time series of four climatological variables: mean temperature $\left({ }^{\circ} \mathrm{F}\right)$, minimum temperature $\left({ }^{\circ} \mathrm{F}\right)$, maximum temperature $\left({ }^{\circ} \mathrm{F}\right)$, precipitation (in) and $\mathrm{P}$. vivax malaria incidence in the province of Alto Amazonas, which is located in the jungle, during 1999-2006.

Click here for file

[http://www.biomedcentral.com/content/supplementary/14752875-8-142-S7.jpeg]

\section{Additional file 8}

Wavelet power spectrum of $P$. falciparum time series in mountain regions. The wavelet power spectrum of the time series of $\mathrm{P}$. vivax (19992006) for the provinces with the highest P. vivax malaria burden in mountain regions. Whereas annual cycles are the dominant pattern, strong biennial cycles can only be observed in a few of the provinces in mountain regions.

Click here for file

[http://www.biomedcentral.com/content/supplementary/1475-

2875-8-142-S8.jpeg]

\section{Additional file 9}

Correlation between precipitation and minimum temperature in three provinces representative of jungle, coastal and mountain regions. The correlation between precipitation and minimum temperature in three provinces that representative of jungle (Alto Amazonas), coastal (Ayabaca) and mountain (Acomayo) regions in Peru. The blue dashed line is a spline curve to highlight a significant correlation trend.

Click here for file

[http://www.biomedcentral.com/content/supplementary/1475-

2875-8-142-S9.jpeg]

\section{References}

I. Malaria Fact Sheet. World Health Organization [http:// www.who.int/mediacentre/factsheets/fs094/en/index.html]

2. Hommel M: Towards a research agenda for global malaria elimination. Malar J 2008, 7(SuppI I):SI.

3. Aramburu Guarda J, Ramal Asayag C, Witzig R: Malaria reemergence in the Peruvian Amazon region. Emerg Infect Dis 1999 , 5:209-2I5.

4. Roberts DR, Laughlin LL, Hsheih P, Legters LJ: DDT, global strategies, and a malaria control crisis in South America. Emerg Infect Dis 1997, 3:295-302.

5. Dirección General de epidemiología. Sistema de vigilancia epidemiológica: Etapas de la vigilancia epidemiológica. [http:// www.dge.gob.pe/ve etapas.php]. Accessed 09 August 2007. 
6. Wikipedia: Provinces of Perú [http://en.wikipedia.org/wiki/ Provinces of Perú]

7. National Institute of Statistics and Informatics (Projection from 1993 census) [http://www.inei.gob.pe]

8. Wikipedia. Surface areas of Provinces in Perú [http://es.wiki pedia.org/wiki/Perú]

9. MeteoRed. Climate data for Perú [http://clima.meteored.com/ clima-en-America\%20del\%20Sur-Perú-PR.html]

10. Daubechies I: Ten lectures on wavelets Philadelphia: SIAM; 1992.

II. Torrence C, Compo G: A practical guide to wavelet analysis. Bull Am Meteor Soc 1998, 79:61-78.

12. Maraun D, Kurths ]: Cross wavelet analysis: Significance testing and pitfalls. Nonlinear Proc Geophys 2004, I I:505-5 I4.

13. Anderson RM, May RM: Infectious diseases of humans NewYork: Oxford University Press; 1991.

14. Rhodes CJ, Anderson RM: Power laws governing epidemics in isolated populations. Nature 1996, 381:600-602.

15. Keeling MJ, Grenfell BT: Disease extinction and community size: modeling the persistence of measles. Science 1997, 275:65-67.

16. Bjornstad O, Finkenstadt B, Grenfell B: Dynamics of measles epidemics: Estimating scaling of transmission rates using a time series SIR model. Ecol Monogr 2002, 72:169-184.

17. Lee WC: Characterizing exposure-disease association in human populations using the Lorenz curve and Gini index. Stat Med 1997, 16:729-739.

18. Woolhouse ME, Dye C, Etard JF, Smith T, Charlwood JD, Garnett GP, Hagan P, Hii JL, Ndhlovu PD, Quinnell RJ, Watts Ch, Chandiwana SK, Anderson RM: Heterogeneities in the transmission of infectious agents: implications for the design of control programs. Proc Natl Acad Sci USA 1997, 94:338-342.

19. Kerani RP, Handcock MS, Handsfield HH, Holmes KK: Comparative geographic concentrations of 4 sexually transmitted infections. Am J Public Health 2005, 95:324-330.

20. Green CG, Krause D, Wylie J: Spatial analysis of campylobacter infection in the Canadian province of Manitoba. Int J Health Geogr 2006, 5:2.

21. Grenfell BT, Bjørnstad ON, Kappey J: Travelling waves and spatial hierarchies in measles epidemics. Nature 200I, 4|4:7|6-723.

22. Cazelles B, Chavez M, Magny GC, Guégan JF, Hales S: Timedependent spectral analysis of epidemiological time-series with wavelets. J R Soc Interface 2007, 4:625-636.

23. Pascual M, Cazelles B, Bouma MJ, Chaves LF, Koelle K: Shifting patterns: malaria dynamics and rainfall variability in an African highland. Proc Biol Sci 2008, 275:123-132.

24. Chaves LF, Kaneko A, Taleo G, Pascual M, Wilson ML: Malaria transmission pattern resilience to climatic variability is mediated by insecticide-treated nets. Malar J 2008, 7:100.

25. Grinsted A, Moore JC, Jevrejeva S: Software for Cross Wavelet and Wavelet Coherence. [http://www.pol.ac.uk/home/research/ waveletcoherence].

26. Wearing $\mathrm{HJ}$, Rohani P: Ecological and immunological determinants of dengue epidemics. Proc Natl Acad Sci USA 2006, 103:11802-11807.

27. Zhou G, Sirichaisinthop J, Sattabongkot J, Jones J, Bjørnstad ON, Yan G, Cui L: Spatio-temporal distribution of Plasmodium falciparum and p. Vivax malaria in Thailand. Am J Trop Med Hyg 2005, 72:256-262.

28. Guerra CA, Gikandi PW, Tatem AJ, Noor AM, Smith DL, Hay SI, Snow RW: The limits and intensity of Plasmodium falciparum transmission: implications for malaria control and elimination worldwide. PLoS Med 2008, 5:e38.

29. McKenzie FE, Killeen GF, Beier JC, Bossert WH: Seasonality, parasite diversity and local extinctions in Plasmodium falciparum malaria. Ecology 200I, 82:2673-268I.

30. Bautista CT, Chan AS, Ryan JR, Calampa C, Roper MH, Hightower AW, Magill AJ: Epidemiology and spatial analysis of malaria in the Northern Peruvian Amazon. Am J Trop Med Hyg 2006 , 75:1216-1222

31. Durand S, Marquino W, Cabezas C, Utz G, Fiestas V, Cairo J, Puray M, Lucas C, Salas C, Gutierrez S, Arrospide N, Bacon DS, Ruebush TK 2nd: Unusual pattern of Plasmodium falciparum drug resistance in the northwestern Peruvian Amazon region. Am J Trop Med Hyg 2007, 76:6 I4-6I8.
32. Maitland K, Williams TN, Bennett S, Newbold Cl, Peto TE, Viji J, Timothy $R$, Clegg JB, Weatherall DJ, Bowden DK: The interaction between Plasmoidum falciparum and $P$. vivax in children on Spiritu Santo island, Vanuatu. Trans R Soc Trop Med Hyg 1996, 90:614-620.

33. Maitland $\mathrm{K}$, Williams TN, Newbold $\mathrm{Cl}$ : Plasmodium vivax and $\boldsymbol{P}$. falciparum: Biological interactions and the possibility of cross-species immunity. Parasitol Today 1997, 13:227-231.

34. Zhou G, Minakawa N, Githeko AK, Yan G: Association between climate variability and malaria epidemics in the East African highlands. Proc Natl Acad Sci USA 2004, 101 :2375-2380. Erratum in: Proc Natl Acad Sci USA 2004, I 0 I: 13694.

35. Hay SI, Myers MF, Burke DS, Vaughn DW, Endy T, Ananda N, Shanks GD, Snow RW, Rogers DJ: Etiology of interepidemic periods of mosquito-borne disease. Proc Natl Acad Sci USA 2000, 97:9335-9339.

36. Hay SI, Shanks GD, Stern DI, Snow RW, Randolph SE, Rogers DJ: Climate variability and malaria epidemics in the highlands of East Africa. Trends Parasitol 2005, $21: 52-53$.

37. Guthmann JP, Llanos-Cuentas A, Palacios A, Hall AJ: Environmental factors as determinants of malaria risk. A descriptive study on the northern coast of Perú. Trop Med Int Health 2002, 7:518-525.

38. Snounou G, Viriyakosol S, Jarra W, Thaithong S, Brown KN: Identification of the four human malaria parasite species in field samples by the polymerase chain reaction and detection of a high prevalence of mixed infections. Mol Biochem Parasitol 1993, 58:283-292.

39. Postigo M, Mendoza-León A, Pérez HA: Malaria diagnosis by the polymerase chain reaction: a field study in south-eastern Venezuela. Trans R Soc Trop Med Hyg 1998, 92:509-5II.

40. O'Meara WP, Barcus M, Wongsrichanalai C, Muth S, Maguire JD, Jordan RG, Prescott WR, McKenzie FE: Reader technique as a source of variability in determining malaria parasite density by microscopy. Malar J 2006, 5: I 18.

4I. Meek SR, Doberstyn EB, Gaüzère BA, Thanapanich C, Nordlander E, Phuphaisan S: Treatment of falciparum malaria with quinne and tetracycline or combined mefloquine/sulfadoxine/ pyrimethamine on the Thai-Kampuchean border. Am J Trop Med Hyg 1986, 35:246-250.

42. Looareesuwan S, White NJ, Chittamas S, Bunnag D, Harinasuta T: High rate of Plasmodium vivax relapse following treatment of falciparum malaria in Thailand. Lancet 1987, 2: 1052-1055.

43. McKenzie FE, Bossert WH: Mixed-species Plasmodium infections of humans. J Parasitol I997, 83:593-600.

44. McKenzie FE, Sirichaisinthop J, Miller RS, Gasser RA Jr, Wongsrichanalai $C$ : Dependence of malaria detection and species diagnosis by microscopy on parasite density. Am J Trop Med Hyg 2003, 69:372-376.

45. Cohen JE: Heterologous immunity in human malaria. $Q$ Rev Biol 1973, 48:467-489.

46. McKenzie FE, Bossert WH: Multispecies Plasmodium infections of humans. J Parasitol 1999, 85:12-18.

47. Earle WC: Epidemiology of malaria in Puerto Rico. Puerto Rico Journal of Public Hygiene and Tropical Medicine 1939, I 5:3-27.

48. Hill RB, Cambournac FJC, Simoes MP: Observations on the course of malaria in children in an endemic region. Am J Trop Med Hyg 1943, 23: 147-162.

49. Bruce-chwatt LJ: A longitudinal survey of natural malaria infection in a group of West African adults: Part I. West African Med J 1963, 12:141-173.

50. Boyd MF, Kitchen SF: Simultaneous inoculation with Plasmodium vivax and Plasmodium falciparum. Am J Trop Med Hyg 1973, |7:855-86|.

5I. Gilles HM, Warrell DA, Eds: Essential Malariology 3rd edition. London: Arnold; 1993.

52. Baird JK: Real-world therapies and the problem of vivax malaria. N Engl J Med 2008, 359:260I-2603.

53. Williams HA, Vincent-Mark $A$, Herrera $Y$, Chang OJ: A retrospective analysis of the change in anti-malarial treatment policy: Peru. Malar J 2009, 8:85.

54. Gunewardena DM, Carter R, Mendis KN: Patterns of acquired anti-malarial immunity in Sri Lanka. Mem Inst Oswaldo Cruz 1994, 89:63-65. 
55. Zhou M, Liu Q, Wongsrichanalai C, Suwonkerd W, Panart K, Prajakwong S, Pensiri A, Kimura M, Matsuoka H, Ferreira MU, Isomura S, Kawamoto F: High prevalence of Plasmodium malariae and Plasmodium ovale in malaria patients along the Thai-Myanmar border, as revealed by acridine orange staining and PCR-based diagnoses. Trop Med Int Health 1998, 3:304-3I2.

56. Mason DP, McKenzie FE: Blood-stage dynamics and clinical implications of mixed Plasmodium vivax-Plasmodium falciparum infections. Am J Trop Med Hyg 1999, 61:367-374.

57. Smith DL, Dushoff J, McKenzie FE: The risk of a mosquito-borne infection in a heterogeneous environment. PLOS Biol 2004, 2:e368.

58. Chowell G, Torre CA, Munayco-Escate C, Suárez-Ognio L, LópezCruz R, Hyman JM, Castillo-Chavez C: Spatial and temporal dynamics of dengue fever in Peru: 1994-2006. Epidemiol Infect. 2008, 136(12):1667-1677.

Publish with Bio Med Central and every scientist can read your work free of charge

"BioMed Central will be the most significant development for disseminating the results of biomedical research in our lifetime. "

Sir Paul Nurse, Cancer Research UK

Your research papers will be:

- available free of charge to the entire biomedical community

- peer reviewed and published immediately upon acceptance

- cited in PubMed and archived on PubMed Central

- yours - you keep the copyright

Submit your manuscript here:

http://www.biomedcentral.com/info/publishing_adv.asp
BioMedcentral 